\title{
ROMANIAN CONSUMER PERCEPTION TOWARDS MOBILE MARKETING CAMPAIGNS
}

\author{
Iacob Cătoiu ${ }^{l}$ \\ Daniel Adrian Gârdan ${ }^{2}$
}

\begin{abstract}
The present article highlights the main aspects concerning consumer perception towards mobile marketing campaigns. The qualitative research conducted by the authors complete their earlier findings regarding future trends of mobile marketing and mobile media. For the Romanian market, mobile marketing campaigns and new communication techniques based upon mobile broadband are at the very beginning, mobile phone service providers and advertiser using little from the wide range of promotional possibilities offered by the new communication technology. Such as research results show, the perception of the Romanian consumers towards specific mobile marketing techniques is influenced primarily by perceptions towards mobile services in general, and there are still no brand images being associate with this new advertising channel. Yet there is consumers' willingness to use new communication channels if the messages are highly personalized and with a great extent of addressability depending on user characteristics. Evolution of marketing theory and practice in time has pointed out that marketing is a science that finds in technology a great ally, and one of the most important source for developing new concepts and applications. As regarding mobile marketing this aspect is even more conclusive because at his very root, mobile marketing is a technology driven domain.
\end{abstract}

Key words: mobile marketing, qualitative research, brand awareness, consumer attitude.

JEL codes: M37, M31.

\section{Introduction}

Currently mobile technology dynamic, offers marketing professionals new opportunities for implement marketing communication strategies.

Advertising on mobile phones becomes more and more important. This was the conclusion of the roundtable of Mobile Worl Congress held this year in Barcelona, attended by the representatives of the four biggest companies implied in mobile marketing activities - Alcatel Lucent, Microsoft, Velti and TurkCell. The Congress has pointed out that recent acquisition of Google and Apple in the mobile space is an undeniable sign that mobile advertising will increase dramatically and that MMA (Mobile Marketing Association) is working with mobile operators association (GSMA) initiative to establish standards for measuring mobile advertising ${ }^{3}$.

The global penetration of mobile phones rose significantly from $79.1 \%$ to $87.2 \%$, between 2004 and 2007 (MobileYouth 2005) ${ }^{4}$.

The same source stated that at the level of 2010, the percent of penetration level of using mobile phones among youth world population (14 to 29 years of age) is between $49 \%$ in Uganda up

\footnotetext{
${ }^{1}$ Romanian Academy of Economic Studies, Bucharest, iacob_catoiu@yahoo.com

${ }^{2}$ Romanian Academy of Economic Studies, Bucharest, danielgardan@yahoo.com

${ }^{3}$ www.mobileworldcongress.com

${ }^{4}$ www.mobileyouthreport.com
} 
to $246 \%$ in Qatar. (from this respect Romania states at the 13 'th place with a rate of $140 \%$ penetration among young users).

With such a high percentages of the world's population owning a mobile phone, marketers from all over the world have the ability to communicate offers directly to the target audience whenever and wherever they may be, offering much more personalised services.

The high rates of young people using one orr multiple mobile networks accounts offers a large mass of potential for all kinds of marketing related aplications, software, etc, and most important of all, the posibility for marketers to develop and control new types of attitude and consumption habbits

Opportunities in wireless marketing and advertising have therefore risen a great deal due to higher penetration, also interactions between consumer and advertiser have been increasing rapid and easy.

\section{Literature review}

The academic literature regarding mobile marketing has been tremendously increasing in the last decade, various researchers contributed to define and shape the concepts referring to the area of mobile channels from the marketing perspective.

That is why we present a few general directions of research in the field, pointing out only the main subjects of concern regarding the potential of mobile marketing, mobile media, the consumer interactions with these new channels and integration of mobile marketing techniques in the marketing activity as a whole.

Mobile marketing ca be defined as "using a wireless medium to provide consumers with time- and location sensitive, personalized information that promotes products, services and ideas, thereby benefiting all stakeholders.'(Scharl, A., Dickinger A., Murphy, J. 2005)

If we take into consideration the classical definition of AMA: "Marketing management is the process of planning and executing the conception, pricing, promotion and distribution of goods, services, and ideas to create exchanges that satisfy individual and organizational goals", we can assume that it implies sequential marketing stages as well as temporal and spatial separation of buyers and sellers. Mobile devices blur these boundaries and distinctions by extending traditional marketing's time-space paradigm. As with other forms of digital marketing, mobile media incorporate interactivity and transcend traditional communication, allowing for one-to one, manyto-many and mass communication models

Mobile Marketing enhances consumer-brand relationship, the interaction between consumers and their mobile phones, together with the ability afforded by mobile advertising to control the viewing environment provides advertisers with an opportunity to build more meaningful brand relationships than at anytime in advertising history (Aaker J.L., Benet- Martinez V. and Garolera J., 2001).

Mobile phones are thus regarded not only as delivery platforms, but also as a way to connect the platform with mass media and points of sale, and can therefore be successfully implemented to help lead the consumer to a purchase. Mobile phones are also ideal mechanisms for marketing because of their seamless integration as a direct email channel to the target audience (Fujita A., 2008).

Today, individuals maintain a hyper - personnel and interactive relationship with their cellular phone (Babinet G., Despres J.C., Gastaldi F. 2003). That is why if a certain company aims the strategic objective to address particularly at a specific target audience, messages through mobile phones can be the ideal instrument 
Mobile phones are usually carried everywhere and kept within reach of their owners. They are ideal for use in conjunction with a variety of traditional media tools such as indoor and outdoor advertising and broadcast channels (Fujita A., 2008).

The appearance of the services "opt - in" SMS has the ability to quickly inform the subscribers of the availability of a promotion or of an innovative service. It is an effective medium to generate traffic by motivating a determined target to contact a call center or to visit a point to sell.

Mobile phones have the potential to be ideal personalized tools for providing an opportunity for marketers to send an offer at the right time to the right consumer (Barutçu, S. 2007).

As we have shown in our further article ${ }^{5}$, a series of conclusions regarding future mobile marketing trends and evolution could be stated:

- the efficiency of mobile marketing technique used and the effect on consumer attitude and habits will be the main concern for marketing specialists in the field

- implementation of a mobile marketing strategy correlated with the whole marketing mix offline and online it is a primary condition for success, because it has been shown that different marketing goals cannot be achieved without an integrated approach

- strong investment in marketing research regarding creative ways of using the new arriving mobile technologies (LTE, HSPA, etc) is needed

- adapting the mobile marketing content to the companies portfolio of different responsiveness groups of customers is one of the main and in the same time, complex task for marketing managers.Theories of inovation diffusion and acceptance have been completed with researches that shows another type of variables that influence consumer responsiveness, and feedback.The main concern has to be targeting the right consumer with the right message content, othervise, especially in time, the consumer response is much more dramatic compared with the situation of other marketing channels.

\section{Research methodology}

The present research was conceived as a focus group type research aimed to investigate and explore some of the perceptions of urban mobile services consumers towards mobile marketing campaigns.

As objectives the research assumed: identifying the degree of satisfaction associated with mobile telephone services in general, usage habbits for mobile phones, perception towards mobile phone advertising, perception towards different mobile services connected with mobile marketing field, identifying ways for measuring the succes of mobile marketing campaigns, notoriety for brands that have been involved in mobile marketing campaigns, what is the relation and connection between online advertising and mobile marketing campaigns,

Participants were carefully selected from among consumers of mobile services in Bucharest, with ages between 20 and 45 years, based on a filter type questionaire.

The sample structure was equilibrated regarding age and sex, also between people who own at least one subscription to a mobile phone provider and those who have a rechargeable mobile phone card.

Were held three working sessions, each with 12 participants, recorded audio-video and transcripted for analyse.The main goal of the research was an exploratory one, beeing the first attempt of the authors to determine some variables and qualitative informations relevant for future attempts conducted also in the quantitative research field.

\footnotetext{
${ }^{5}$ Cătoiu Iacob, Gârdan Daniel Adrian, Gârdan Doru Lucian - Mobile marketing future trends, Annals of Spiru Haret University, economic series, volume 1 (10),issue 1,2010,Romania de Maine Foundation printing house
} 
A general observation is that the participants were very alert and involved in discussions, wich denote the importance in their everyday consumption universe related to mobile phone services

As conclusions of the research for the first topic - the degree of satisfaction associated with mobile telephone services in general at the level of conversation guide were pointed out the next assumptions:

- a great proportion of the participants that are old subscriptions owners are not generally satisfied with their main provider - even the emotional reaction was very powerfull and spontaneous

- attributes that define satisfaction are mainly cost per minute, the ammount of free minutes, and personalized cost per minute for the same operator calls orr different operators

- there is a strong opinion regarding the statute of „loyal and old client” and expectations related to it:they are not satisfied because the statute is not clearly recognised and rewarded by the mobile providers, participants epspect greater benefits from every minute spend over the mobile network

- consumers develop a personal strategy for achievieng as they interesting calling it „, an artificial satisfaction" by negotiating firm the conditions for renouncing at their own subscription. Almost every participant have this experience at least for one time - they declare to the provider that are unsatisfied with their actual subscription, forcing it to offer custom tariffs for each one. It is interesting that after achieving their goals they declare themselves artificially satisfied.

- Suggestions - creating a database with consumers and their devices owned at a time and providers propose special acquisition prices for new device at a specific period of time - eg 3 months, 6 months, etc

- Perception toward client service for any provider is considerable low, regarding time needed to obtain an information,

- A better communication for every consumers regardless their time spend as active clients for the operator - in case of losing the phone or mobile card,

- Website interface has serious weaknesses, regarding content, functionality, user friendly design - an important attribute for consumer's satisfaction is the versatility of such instruments as websites because as will be stated later it can be observed an increased correlation between online content and mobile phones

Next topic of discussion was usage habits for mobile phones. Participants have a great deal of frequency for using the mobile phone, an average of the amount of calls time for a day being at 3 hours. Despite the qualitative type of the research that makes impossible the statistical relevance it is noticeable that emotionally all the participants are very deep implied in using mobile phone, it becomes a proven reality the fact that using mobile phone is not an simple everyday need, a necessity, but a way of life, a meaning of personality expression for everyone - that conclusion is very important from the point of view of mobile marketing as we stated before the interactivity offered by marketing techniques used in mobile marketing is sustained by the very high degree of the consumer involvement.

Other ways of using mobile phones (in order of preference) - SMS and MMS, radio listening, music, snooze watch, gps, web browsing. At this point was stated the fact that younger users adapt their habits to the new technical features of the phones much better and fast

From the point of view of the perception towards advertising through mobile phones, opinion is very differentiated between extremes, there are users that consider advertising through mobile phone generally useful because of an economy of time and money, and some other users that consider advertising through mobile phones useless, they have a real jam, when they talk about it.It is an entire field of deeper research for mobile marketing specialists, the reasons of consumers that 
don't want to accept advertising through mobile phones. From the point of view of our research, possible reasons identified are related with the lack of confidence in information delivered through these channels, rumors from other users who have experienced mobile fraud.

Users that found useful advertising through mobiles are still very cautions related with some particular services - among them, banking through mobile phones is considered risky.

Regarding the frequency of advertising messages it is a common opinion that the high frequency of messages could lead to their rejection. The focus group participants stated that they received an average of three SMS advertising messages in the last month, and around 20-25 advertising messages in the last six months.

From this amount of total messages, the proportion of messages that could be associated with the status of well targeted messages for the considered consumers was around $12-15 \%$.

Another interesting conclusion is about the criteria used to measure from the consumers' point of view the extent to which a message was well targeted.

Thereby, most important criteria is considered the willingness to receive promotional messages on mobile phone, then the brand criteria, age, sex, income, location. The age and sex criteria is considered one of the most important criteria because messages can be very different related to this.

When asked which are brands that were promoted through mobile phones there are some well known brands, without a well establish relation between them and respondents - Philip Morris, Domo, Coca Cola, Blue Air, credit card designed for shopping.

Just in one case - Domo promotion, the person concerned after receiving the SMS promotional message has bought a printer from Domo store and the degree of satisfaction was indeed high.

It is noticeable that no one from the participants were not questioned by the operators in terms of availability to receive messages for available brands.

The topic concerning brands, categories of products or services which are considered appropriate for promoting using mobile phones has revealed names as Zara, Mango, House of Art, Musette, Tarom, Blue Air, Diverta. As categories of products or services there are: beauty salons, pharmacies, gyms, swimming-pools. In the last case was take into consideration differences between levels of price, and very diversified offer, which leads to the need for prompt information. Advertising thorough mobile is considered a fast and easy channel of communication in this case.

Another type of services considered appropriate for mobile channel promotion is auto parks due to the high demand in the urban area.

At this point of discussion a particular topic has been the promotion of social services through mobile media channels. Given the degree of mobile services spread among consumers with middle and low income in Romanian urban areas, promoting social services as job offers, employment assistance, etc could be a very efficient solution. The focus groups participants were emotionally involved into the discussion regarding the lack of involvement in social campaigns of mobile operators. Everybody agrees that mobile phones services providers should take a strong position for implementing social campaigns delivering multiple benefits to consumers. Even mechanism such as a little tax for every SMS/MMS promotional message for all kinds of brands to be used in the social responsible way.

A single example of advertising agency was taken into consideration: McCann Erickson who have a contract with Petrom and Vodafone regarding a mobile campaign. The awareness of the campaign was due to a consumer loyal to Petrom products and services

As for mobile marketing campaigns - the campaign for Kent, car freshness and Cosmote and Vodafone anti mobile fraud campaigns were remembered by the respondents 
An interesting idea was that any big company should do promotion over the mobile channels - the motivation was due to the high extent of competition and companies have to use every bit of communication way to reach to the consumers.

From the point of view related to the cross promotion of a product/brand/service, etc using offline, classical channels and online and mobile ones the conclusion was that it is far more useful for the participants to have advertising via email received over the mobile phone, than advertising SMS or MMS. The content of a newsletter, or special offer is far more attractive than the 256 characters of a MMS, a single picture, etc. Taking into account the new possibilities offered by the mobile smart phones and mobile communication technologies, access over the internet and web browsing is becoming more and more versatile and simple. In this case promoting a brand over mobile internet could be, is true far more effective than using simple SMS or even MMS service.

Mobile phone service providers, producers, mobile games developers, mobile applications developers, mobile phones accessories and devices producers, etc should have their own mobile marketing strategy, participants consider that as competition increasing, the mobile channel offers an important potential, being insufficient used.

Unconventional mobile advertising techniques were considered the banners included into Iphone applications that every I-phone user can see and interact with it. As a remark, there are many mobile phones applications designed also for Symbian, Android or Windows Mobile that are using the same technique - this could be another branch of future research to take into consideration „the efficiency of advertising through banners incorporated in mobile phone applications”.

Another example of unconventional techniques for mobile advertising is that a trader can use SMS advertising and if the consumer reach the shop, and he presents the SMS received can benefit from different discounts or even the amount of money necessary for the trip to the shop.

The participants seems to be very creative when they have been asked to express ideas related to new ways of advertising - the need to personalize messages through a human interface - a person to speak to the mobile phone user, to announce the offer or the promotion itself

\section{Conclusions}

The principal problem related with the application of mobile marketing remains the consumers' attitude towards mobile advertising, the way that any potential target respond to different types of messages delivered with this channel.

After a considerable period of tryouts and in field experiments, marketers have found that the new type of mobile advertising despite its concrete qualities has also some major restrains.

Consumers generally have negative attitudes toward mobile advertising unless they have specifically consented to it, (Tsang, 2004), there is a direct relationship between consumer attitudes and consumer behavior. Thus it is not a good idea to send SMS advertisements to potential customers without prior permission.

Mobile advertising and Internet advertising have many features in common-both are emerging media used to deliver digital texts, images, and voices with interactive, immediate, personalized, and responsive capabilities (Yoon, S.J., and Kim, J.H, 2001).

Because of the technical specifications and based on different strategic applications, wireless (mobile) marketing can be either permission-based, incentive-based, or location-based (Zoller, E.; Housen, V.L.; and Matthews, J.2001).

Permission-based advertising differs from traditional iritative advertising in that messages about specific products, services, or content are sent only to individuals who have explicitly indicated their willingness to receive the message. Consumers often impatiently ignore the message when interrupted by an advertisement. By relying on the permission of the target audience, permission-based advertising focuses on reducing the irritation. 
Incentive-based advertising provides specific financial rewards to individuals who agree to receive promotions and campaigns. For example, mobile phone companies may reward customers with free connection time for listening to voice advertisements. Both permission-based and incentive-based advertising mechanisms are feasible for mobile advertising because the wireless technology makes it possible to identify individual users.

In addition to individual identification, mobile technology also makes it possible to locate a particular consumer.

Location-based advertising takes advantage of this feature to target people in a certain location. Advertisements are sent based on where the user is or where the user is going (Zoller, E.; Housen, V.L.; and Matthews, J.2001).

The evolution of mobile marketing content can be generally summarized on the following directions:

\section{A. Using the Shorts Message Service (SMS)}

The Shorts Message Service (SMS) is an immediate, automated, reliable, personal, discreet and customized channel (Karjaluoto H., Leppaniemi and Salo., 2008).

Mobile telephone companies plan to use SMS for customer relationship management, sending their clients information on where to get cheap pre-paid phone cards when their credits are running low.

Companies can send coupons to cell phones via SMS. So mobile couponing offers at least three advantages: targeting based on customer cell phone numbers; time sensitivity, e.g. receiving a $20 \%$ discount on purchases immediately after entering a shop; and efficient handling by scanning the coupon's bar-code at the cash desk. It has been shown that the rates of percent coupon from a total of a company can get close to $11 \%$ in some cases (www.borders.com coupon campaign).

Talking about the efficiency of SMS advertising, compared to click-through rates of less than $1 \%$ for online advertising [Hanson, W. 2000), wireless click-through rates and call-through rates are $19 \%$ and $12 \%$, respectively.

\section{B. Developing Brand Image Campaigns}

Although if we take into considerations the limitations of SMS - the text is simply limitated to a 160 number of characters, specialists began to develop brand image campaign using a SMS campaign correlated with online and offline classical promotional efforts.

The key to implement a real scale brand image campaign resides in using the much evolved technology of MMS (Multimedia Messaging Service) that allows targeted personalised messages with multimedia (audio, video, text) content, and the posibility to have full online acces to web pages content related with the message itself.

It has been stated that trusted brands are more and more important in the virtual world where they influence online purchases, generate customer loyalty (Clifton, R.2002), and attract customers to their Web sites. This 'virtual branding' effect may apply to SMS and MMS as well.

Broadband access and advanced mobile devices will enable multimedia content access for a very large mass of auditorium and thus increase image campaign possibilities.

Real time transmission, whereby the message appears on the potential consumer's screen within seconds, will further increase mobile marketing success. These instantaneous broadcasts offer opportunities, such as ordering songs played on the radio instantly after hearing them.

\section{Integrated mobile marketing mix}

The future trend for mobile marketing is related to the capacity of different companies to integrate different elements of the mobile marketing mix into a strong objectives driven strategy. From this point of view, the best thing to do is to start the mobile marketing effort with a SMS campaign, followed up with a mobile Web site, mobile advertising and mobile couponing. 
After implemeting the above steps it is imperious to have a sustenable campaign of incentives for the consumers that has been active for all the period of campaign.

\section{High consumer responsiveness}

Maybe the most intriguing and demanding challenge for modern marketers it is the one related with the objective of achieving high consumer responsiveness after mobile marketing activities.

Research conducted so far (Heinonen K; Strandvik T, 2007) stated that message content relevance and channel acceptance are not directly related to high consumer responsiveness. Content relevance in itself did not necessarily mean high responsiveness as the channel may have simultaneously been perceived as disturbing. In contrast, low relevance may also involve some positive responsiveness if the channel for the marketing activity was perceived as accepted.

Consumers expect messages to be personal and of high interest and this makes the disappointment greater when they get undesired messages.

A firm's customers may be divided into a portfolio of different responsiveness groups. By looking at consumer responsiveness as a function of disturbance and relevance it is possible to see four different situations for increasing the likelihood of getting the consumers' attention, as we can see in the figure below.

It is the most important thing at the level of choosing right design for messages, right timing, to take into consideration different type of consumers responsiveness. The mobile marketing strategy itself should be conducted by this kind of results.

Fig. no. 1. Communication strategies based on customer resbonsiveness

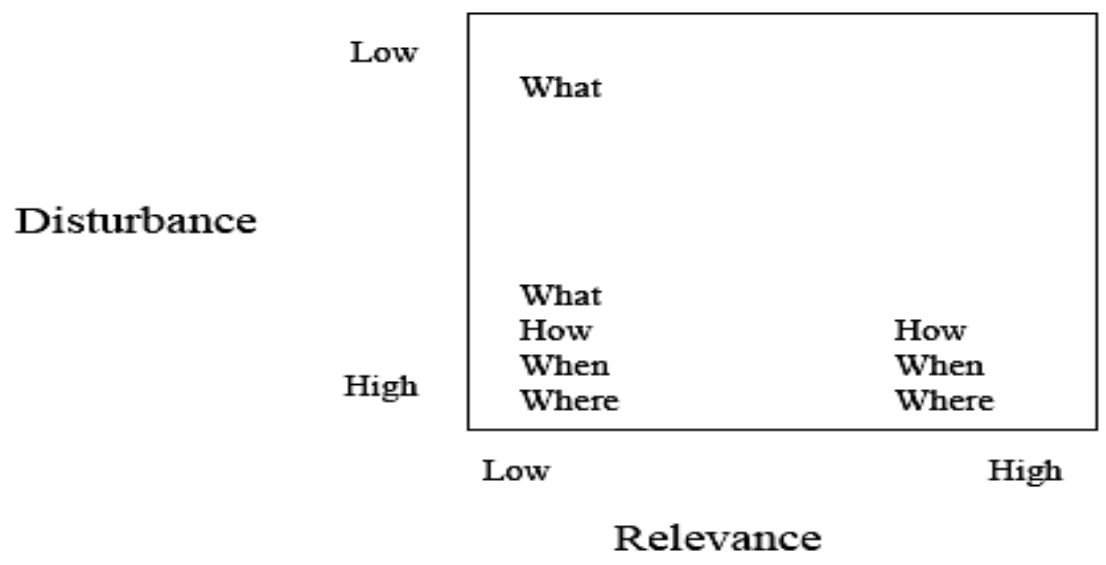

Source: Kristina Heinonen and Tore Strandvik - Consumer responsiveness to mobile marketing, International Journal of Mobile Communications, Volume 5, Number 6 / 2007, p. 615.

\section{E. Emergence of new technologies}

A GSM and its evolution through GPRS, EDGE,WCDMA and HSPA(High Speed Packet Access), is the technology stream of choice for the vast majority of the world's mobile operators. Today 's commercial offerings which are based on this technology evolution typically offer downlink speeds in the order of $7 \mathrm{Mbps}$ (Mega bits per second), with the expectation that $14 \mathrm{Mbps}$ will become widely available in the near future. With such an improvement in 3rd Generation (3G) capabilities, there are obvious questions to be asked about what should happen next.

Users have experienced a dramatic reduction in telecommunication charges and they now expect to pay less but receive more. Therefore, in deciding the next generation in mobile communication, there must be a dual approach: seeking considerable performance improvement but 
a reduced cost. LTE (Long Term Evolution) is the next step and will be the basis on which future mobile communications systems will be built. LTE is the first cellular communication system optimized to support packet -switched data services to enable mobile broadband.

Mobile broadband is becoming a reality, as the Internet generation grows accustomed to having broadband access wherever they go, and not just at home or in the office. Out of the estimated 1.8 billion people who will have broadband by 2012, some two-thirds will be mobile broadband consumers - and the majority of these will be served by HSPA and LTE networks.

People can already browse the Internet or send e-mails using HSPA-enabled notebooks, replace their fixed DSL modems with HSPA modems or USB dongles, and send and receive video or music using $3 \mathrm{G}$ phones. With LTE, the user experience will be even better. It will further enhance more demanding applications like interactive TV, mobile video blogging, advanced games or professional services.

As from the point of view of our present research, Romanian urban consumer of mobile phone services is still not using on a large scale smart phones and actual 3G technology, and this particular aspect leads to a lack of interest regarding mobile advertising campaigns. As the conclusions of the research show, mobile service providers are not perceived as reliable partners in the satisfaction equation of the consumers, and this lead to a kind of resistance in front of mobile promotional efforts.

Still as we stated in the beginning of our article, the mobile marketing has a great potential, Romanian consumers becoming more and more aware of the possibilities offered by actual mobile technology and manifest a tangible interest for alternative advertising channels such as the mobile media one.

\section{References}

1. Aaltonen Aleksi (2010): Making Up Mobile Advertising Audience, proceddings 3rd Latin American and European Meeting on Organization Studies (LAEMOS), 7-10 April 2010, Buenos Aires.

2. Aaker J.L., Benet- Martinez V. et Garolera J. (2001): Consumption symbols as carriers of culture: A study of Japanese and Spanish brand personality constructs, Journal of personality and social psychology, vol. 81, no. 3, p. 492-508.

3. Barwise, P., Elberse A., and K. Hammond (2002): Marketing and the Internet, in Working Paper, Future Media Research Programme, London Business School, London <online:http://www.london.edu/marketing/Future/future_media_research_projects/Untitled/i nternet/ATI_1.3.pdf >

4. Barutçu, S., (2007): Information Technology, Mobile Marketing and Mobile Commerce in Consumer Markets, 3rd International Conference on Business, Management and Economics, June 13-17, Yaşar University, İzmir, TURKEY.

5. Bouhlel O., Mzoughi N., Hadiji D., Slimane I. Ben, (may 2009): Brand Personality and Mobile Marketing: An Empirical Investigation, World Academy of Science, Engineering and Technology, Proceedings, Tokyo, Japan, issue 53, p. 703-710, http://www.waset.org/journals/waset/v53/v53-113.pdf.

6. Cătoiu Iacob, Gârdan Daniel Adrian, Gârdan Doru Lucian: Mobile marketing future trends, Annals of Spiru Haret University, economic series, volume 1 (10),issue 1,2010,Romania de Maine Foundation printing house.

7. Carroll, J., Howard, S., Peck, J., Murphy, J. (2002): A Field Study of Perceptions and Use of Mobile Telephones by 16 to 22 Year Olds, The Journal of Information Technology Theory and Application, Vol. 4, No. 2, p. 49-61. 
8. Clifton, R. (2002): Brands and Our Times, Journal of Brand Management, vol. 9, no. 3, p. 157-161.

9. Dickinger Astrid, Haghirian Parissa, Murphy Jamie, Scharl Arno (2004): An Investigation and Conceptual Model of SMS Marketing, Proceedings of the 37th Hawaii International Conference on System Sciences.

10. Fritze Gerhard Dipl.-Ing. M.Sc. (2008): Customer Solution Manager Ericsson Austria $\mathrm{GmbH}, \mathrm{SAE}$ - The Core Network for LTE, Erricson Press Report.

11. Fujita Akihisa (2008): Mobile Marketing in Japan: The acceleration of integrated marketing communications, Journal of Integrated Marketing Communications, North Western University, p. 41-46.

12. Gyozo Gidofalvi, Hans Ravnkjaer Larsen, Torben Bach Pederse (2008): Estimating the capacity of the Location-Based Advertising channel, International Journal of Mobile Communications, vol. 6, no. 3, p. 357-375.

13. Hans H. Bauer, Stuart J. Barnes, Tina Reichardt, Marcus M. Neumann, (2005): Driving consumer acceptance of mobile marketing: a theoretical framework and empirical study, Journal of Electronic Commerce Research, vol. 6, no.3, p.181-192.

14. Hanson, Ward (2000): Principles of Internet Marketing, South-Western College Publishing, Cincinnati.

15. Hee-Woong Kim, Hock Chuan Chan, Sumeet Gupta, (2007): Value-based Adoption of Mobile Internet: An empirical investigation, Decision Support Systems 43, p. 111-126.

16. Heinonen Kristina, Strandvik Tore (2007): Consumer responsiveness to mobile marketing, International Journal of Mobile Communications, vol. 5, no. 6, p. 603-617.

17. Kai Wehmeyer (2007): Mobile ad intrusiveness - The effects of message type and situation, 20th Bled eConference eMergence: Merging and Emerging Technologies, Processes, and Institutions June 4 - 6, 2007, Bled, Slovenia.

18. Matti Leppäniemi and Heikki Karjaluoto, (2005): Factors influencing consumers' willingness to accept mobile advertising: a conceptual model, International Journal Mobile Communications, vol. 3, no. 3, p.197-213.

19. Melody M. Tsang, Shu-Chun Ho, and Ting-Peng Liang (2004): Consumer Attitudes Toward Mobile Advertising: An Empirical Study, International Journal of Electronic Commerce, vol. 8, no. 3, p. 65-78.

20. Pagani Margherita (2004): Determinants of adoption of third generation mobile multimedia services, Journal of interactive marketing, vol. 18, no. 3, p. 46-59.

21. Payne Adrian, Frow Pennie (2005): A Strategic Framework for Customer Relationship Management, Journal of Marketing, vol. 69, no. 4, p. 167-176.

22. Pousttchi, Key; Wiedemann, Dietmar Georg, 2005, A Contribution to Theory Building for Mobile Marketing: Categorizing Mobile Marketing Campaigns through Case Study Research, Journal of Electronic Commerce Research, Vol. 6, no. 3, ISSN: 1938-9027, p. 160-164.

23. Scharl, Arno., Dickinger Astrid., Murphy Jamie, (2005): Diffusion and success factors of mobile marketing, Electronic Commerce Research and Applications, vol. 4, no. 2, p. 159173.

24. *** (2000). First-to-Wireless: Capabilities and Benefits of Wireless Marketing and Advertising Based on the First National Mobile Marketing Trial, WindWire Inc., Morrisville NC. - http://www.imapproject.org/imapproject/downloadroot/public3.

25. Yoon, S.J., and Kim, J.H. (2001): Is the Internet more effective than traditional media? Factors affecting the choice of media. Journal of Advertising Research, vol. 41, no. 6, p. 5360 . 
26. Teo T.S.H., Pok Siau Heong (2003): Adoption of WAP-enabled mobile phones among Internet users, The International Journal of Management Science, Omega, vol. 31, p. 483498, http://www.bschool.nus.edu.sg/staff/bizteosh/TeoPokOmega2003WAP.pdf

27. Scornavacca Eusebio, Barnes Stuart J, Huff Sid L., (2005): Mobile business research, 20002004: emergence, current status, and future opportunities, 13th European Conference on Information Systems, Information Systems in a Rapidly Changing Economy, ECIS 2005 Proceedings, Regensburg, Germany, May 26-28, 2005, Paper 59.

28. Tähtinen Jaana, Salo Jari (2004): Special Features of Mobile Advertising and their Utilization, Proceedings of the 33rd EMAC Conference, 18-22.5.2004 (CD), Murcia, Spain.

29. Zoller, Eden; Housen, V.L.; Matthews, J. (2001): Wireless Internet business models: Global perspective, regional focus. OVUM 2001 Report, Ovum Ltd, London, ISBN-10: 1902566858 , p. $1-64$.

30. www.mobileyouthreport.com

31. www.mobileworldcongress.com

32. www.comscore.com 